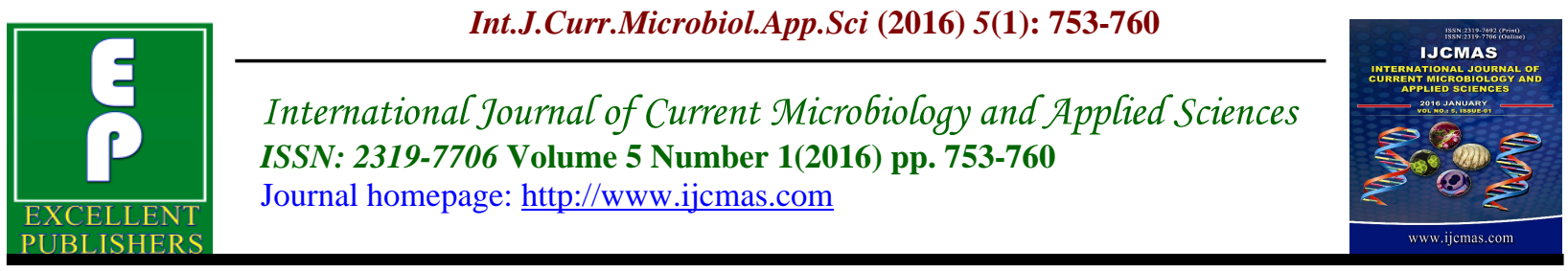

Original Research Article hittp: //dx.doi.org/10.20546/ijcmas.2016.501.076

\title{
Prevalence of Giardia lamblia among Iraqi Displaced Peoples in Kirkuk Province
}

\author{
Yahya Jirjees Salman ${ }^{1}$, Abdul-Rahman Aziz Al-Taee ${ }^{2}$ and Ali Mohammed Abid ${ }^{3}$ \\ ${ }^{1}$ College of Dentistry/Kirkuk University, Iraq \\ ${ }^{2}$ College of Medicine/Tikrit University, Iraq \\ ${ }^{3}$ College of Science/Tikrit University, Iraq
}

*Corresponding author

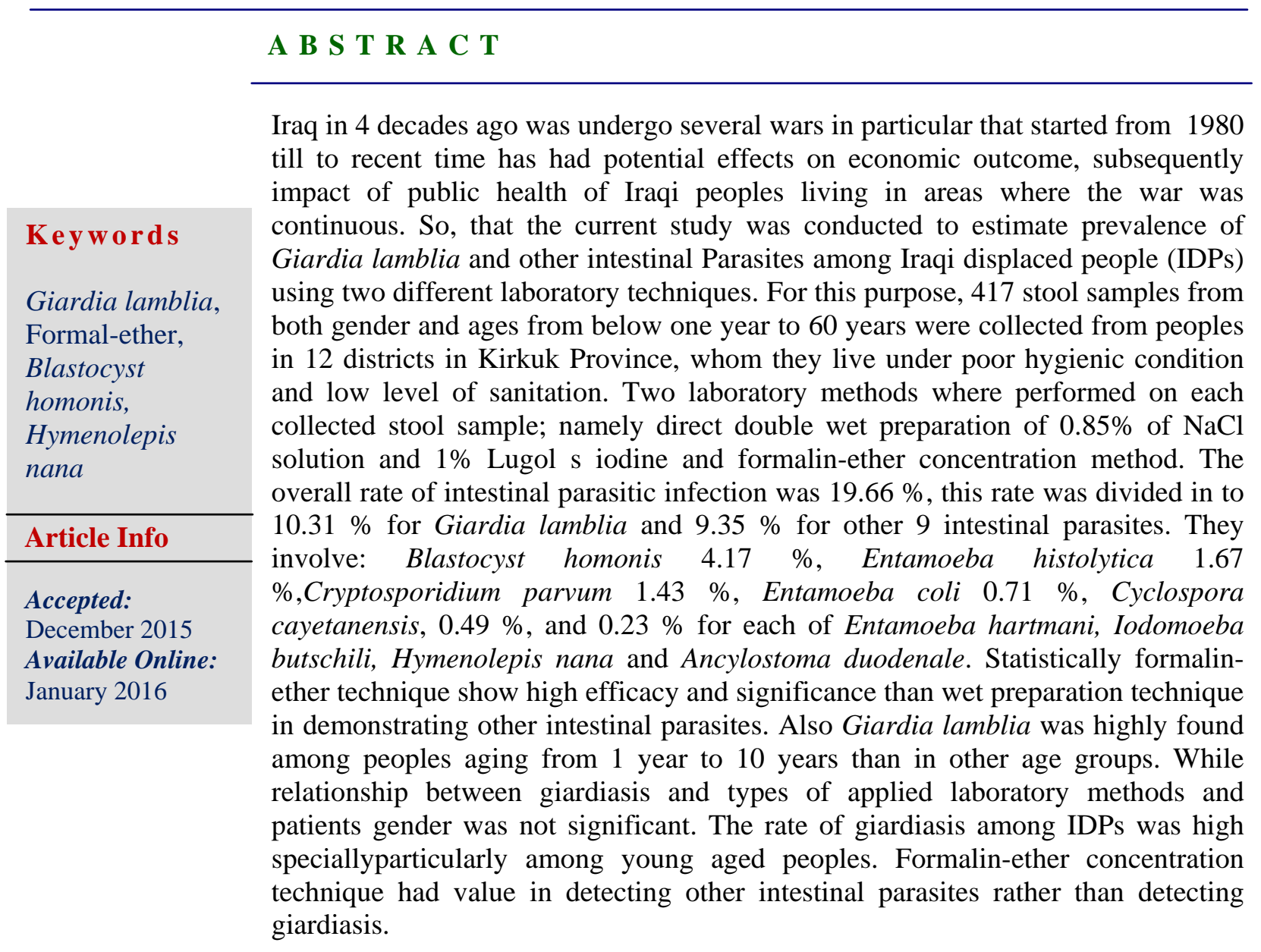

\section{Introduction}

Giardiasis is caused by a flagellate protozoan parasite, Giardia lamblia (order
Diplomonadida, family Hexamitidae) and affects people worldwide including people 
living in developed countries, but is more prevalent in areas with inadequate sanitary conditions(El-Safi,et al 2013). It is one of the most important non-viral infections causing diarrheal illness in humans (Meyer 1990; Dib etal. 2008). Giardia lamblia is recognized as the most common intestinal protozoan parasite infecting humans in Iraq (Abd-Alzahra et al,2012) particularly in Kirkuk Province (Salman and Mustafa, 2013).These diseases are often overlooked during routine parasitological or serological testing of intestinal parasites (Salman and Salih, 2013). Depending on availability of equipment, reagents, technical experience, considerations of time, and cost, there are several methods for the detection of giardiasis (Ndao2010).Microscopic examination of stool samples, either direct or concentrated, for the recovery of $G$. lamblia both stages trophozoites and cysts(CLSI,2005).

The recent crisis and violence lead to massive population movement, and presence of over 1,500,000 internal displaced in Iraq (Xiao et al., 1999). The displacement of populations from different communities often brings people into proximity either due to increased concentrations of displaced populations and also increased density in terms of the living environment (Salman et al, 2015 a). If one group is a carrier of illness, disease outbreaks reflecting endemic pathogens circulating within the community may occur (Watson et al., 2007). Because of the internally displaced persons are at high risk for emerging parasitic infections, since in most cases they have a history of poor utilization of medical care and vaccination, living conditions of low socioeconomic status and a high possibility to be carrying symptomless diseases, so it is important to carry out an assessment for diarrheal risk factors particularly intestinal parasites with an emphasis on Giardia lamblia and to avoid any health risks. Therefore this study was conduct to investigate giardiasis rate in this particular category.

\section{Materials and Methods}

\section{Time and Location}

From 1st of September 2014 to 30th of June of 2015, cross sectional study was conducted in laboratory department of dentistry College Kirkuk University, and in Ibn-Nafies private medical laboratory.

\section{Source of Samples}

A total of 417 stool samples were chosen from internal displaced persons living in schools, houses under construction and rented accommodations and houses in over 12 residential districts in Kirkuk city with variant economical and hygienic levels and those people are originated from different cities and villages like Anbar, Mosul, SalahEldin, Diyala, Fallujah and other areas which severely affected from conflicts and crisis in Iraq. Sample size was validated by applying the equation of sample size determination in unknown population. Patients are segregated into age groups for both males and females subjects by applying Yule method (Danielm, 1985). Also sample chooses were involve two sources: 360 stool samples for peoples living under low level of sanitations, low income and poo hygienic condition. Whereas 57 stool samples for people living in normal goo level of sanitation, high income and good level of hygiene were chosen.

\section{Stool Samples Collection}

Prior to sampling a special questionnaire was filled for each patients consisting of essential information. Disposable container with wide screw lid was given to each 
patient to bring stool samples. The container label contain: name, date, address and number of container. Immediately about 3-5 $\mathrm{ml}$ of Potassium chromate solution was added to each container for preservation (Salman, 2015). Stool samples were kept in ice box and transferred directly to laboratory department for processing.

\section{Sample Processing}

After samples arrival to laboratory, each sample was examined for detecting Giardia lamblia stages and other intestinal parasites stages using direct double wet preparation of $0.85 \%$ of $\mathrm{NaCl}$ and $1 \%$ of lugols iodine (Salman, 2015).While formalin -ether technique was applied as follows: $10 \mathrm{ml}$ of formalin was added in a clean test tube containing approximately $1 \mathrm{gm}$ of stool sample, the tube then agitated for two minutes till to obtaining cloudy suspension. A second centrifuge tube was fixed in a plastic rack and double layer of gauze was fitted in a funnel fixed in the top of centrifuge tube; carefully the content of first tube was converted into the tube on the rack. The funnel and gauze were removed and 3 $\mathrm{ml}$ of ethyl acetate or ether-ether was added quickly and the tube was plugged with rubber. The tube was converted several times then centrifuged for 3 minutes using $3000 \mathrm{rpm}$. The supernatant was discarded and few drops of malachite green $3 \%$ stain or lugols iodine $3 \%$ was added to deposit. The tube was shacked for several times all content of the deposit were examined using $10 \mathrm{X}$ and $40 \mathrm{X},(\mathrm{WHO}, 1991)$.

\section{Results and Discussion}

From the examining of 417 stool samples using direct double wet preparations, the overall rate of the intestinal parasitic infections was $19.66 \%$ distributed in 82 stool samples. This rate involve $10.31 \%$
(43) as pure Giardia lamblia infection and $9.35 \%$ (39) for other intestinal parasitic infections. Statistically the differences between giardiasis and other intestinal parasitic infections in regard of direct microscopy was not significant, $\mathrm{P}>0.05$. Table 1.

Nine species of other intestinal parasites were recorded in current study beside Giardia lamblia. The rates were: $4.176 \%$ for Blastocyst homonis followed by $1.678 \%$, $1.438 \% .0 .719 \%$, and $0.479 \%$ for Entamoeba histolytica Cryptosporidium parvum, Entamoeba coli, Cyclospora cayetanensis. While low rate $0.239 \%$ was recorded for each of Entamoeba hartmani, Iodomoeba butschili, Hymenolepis nana and Ancylostoma duodenale, $\mathrm{P}<0.05$; Table -2 .

To get accurate and more precise rate of giardiasis in addition to assess the efficacy of suitable laboratory methods in detecting Giardia lamblia and other intestinal parasites, the all 417 stool samples were examined using direct double wet preparations in parallel with formalin-ether sedimentation technique. The results were obvious in table-3; which exert $5.51 \%$ of Giadia lamblia stages using ether formalin compare to $4.79 \%$ using double preparations, $\mathrm{P}>0.05$. While other intestinal parasitic rate $6.23 \%$ by using etherformalin technique was higher than $3.12 \%$ using double preparations, $\mathrm{P}<0.05$. Whereas collectively Giadia lamblia and other intestinal parasites statistically show significant differences between to laboratory methods; through which ether-formalin technique contribute $11.75 \%$ from total of $19.66 \%$ for detecting parasitic stages in stool samples compare to $7.91 \%$ by using double wet preparation method, $\mathrm{P}<0.05$.

Regarding the relationship between Giardia lamblia distribution according to patient 
gender, no significant difference was obtained between males and females, $\mathrm{P}>0.05$. Meanwhile according to patients ages high rate of giardiasis $5.99 \%$ was found in stool samples belongs to peoples aging from 1 year to 10 years compare to $0.47 \%$ of giardiasis among patients aging from 41 to 50 years, $\mathrm{P}<0.05$;table- 4 . The overall rate of intestinal parasitic infections
$19.66 \%$ in the present study was high, this reflects: lower educational level to health hygiene among children, poor experience in toilet use, overcrowded families, water contamination with Giardia and other waterborne parasites, and lack of insecticides that had role in mechanical transmission of the infective stages of intestinal parasites.

Table.1 Distribution of Giardia lamblia and other Intestinal Parasites by using Direct Microscopy

\begin{tabular}{|l|l|l|l|l|}
\hline \multirow{2}{*}{ Parasites types } & Positive & Negative \\
\cline { 2 - 5 } & No & \% & No & \% \\
\hline Giardia lamblia & 43 & 10.31 & 347 & 89.61 \\
\hline Other intestinal parasites & 39 & 9.35 & 378 & 90.65 \\
\hline Total & 82 & $19.66^{*}$ & 335 & 80.44 \\
\hline
\end{tabular}

$* \mathbf{P}>\mathbf{0 . 0 5}$

Table.2 Frequency of Other Intestinal Parasites by using Direct Microscopy

\begin{tabular}{|l|l|l|}
\hline Type of parasites & Number positive & Percentages positive \\
\hline Blastocyst homonis & $\mathbf{1 7}$ & $\mathbf{4 . 1 7 6} *$ \\
\hline Entamoeba histolytica & $\mathbf{7}$ & $\mathbf{1 . 6 7 8}$ \\
\hline Cryptosporidium parvum & $\mathbf{6}$ & $\mathbf{1 . 4 3 8}$ \\
\hline Entamoeba coli & $\mathbf{3}$ & $\mathbf{0 . 7 1 9}$ \\
\hline Cyclospora cayetanensis & $\mathbf{2}$ & $\mathbf{0 . 4 7 9}$ \\
\hline Entamoeba hartmani & $\mathbf{1}$ & $\mathbf{0 . 2 3 9}$ \\
\hline Iodomoeba butschili & $\mathbf{1}$ & $\mathbf{0 . 2 3 9}$ \\
\hline Hymenolepis nana & $\mathbf{1}$ & $\mathbf{0 . 2 3 9}$ \\
\hline Ancylostoma duodenale & $\mathbf{1}$ & $\mathbf{0 . 2 3 9}$ \\
\hline Total & $\mathbf{3 9}$ & $\mathbf{9 . 3 5 2}$ \\
\hline
\end{tabular}

*P $\mathbf{P}<.05$

Table.3 Comparison between the Employ of Direct Double Preparations Technique and EtherFormalin Sedimentation Technique in Detecting Giardia lamblia in Stool Samples

\begin{tabular}{|c|c|c|c|c|c|c|c|c|c|c|c|c|}
\hline \multirow[t]{3}{*}{ Lab methods } & \multicolumn{4}{|c|}{ Giardia lamblia } & \multicolumn{4}{|c|}{ Other intestinal parasites } & \multicolumn{4}{|c|}{ Total } \\
\hline & \multicolumn{2}{|c|}{ Positive } & \multicolumn{2}{|c|}{ Negative } & \multicolumn{2}{|c|}{ Positive } & \multicolumn{2}{|c|}{ Negative } & \multicolumn{2}{|c|}{ Positive } & \multicolumn{2}{|c|}{ Negative } \\
\hline & No & $\%$ & No & $\%$ & No & $\%$ & No & $\%$ & No & $\%$ & No & $\%$ \\
\hline $\begin{array}{l}\text { Double wet } \\
\text { preparations }\end{array}$ & 20 & 4.79 & 397 & 95.21 & 13 & 3.12 & 404 & 96.88 & 33 & 7.91 & 384 & 92.21 \\
\hline Ether-formalin & 23 & $5.51 \mathrm{~A}$ & 394 & 94.49 & 26 & $6.23 \mathrm{~B}$ & 391 & 93.27 & 49 & $11.75 \mathrm{C}$ & 368 & 88.25 \\
\hline Total & 43 & 10.31 & 335 & 89.68 & 39 & 9.35 & 378 & 90.65 & 82 & 19.66 & 335 & 80.44 \\
\hline
\end{tabular}

$\mathrm{A}=\mathrm{P}>\mathbf{0 . 0 5} \quad \mathrm{B}$ and $\mathrm{C}=\mathrm{P}<\mathbf{0 . 0 5}$ 
Table.4 Giardia lamblia Distribution in Relation to Patients Age and Gender

\begin{tabular}{|c|c|c|c|c|c|c|c|c|c|c|}
\hline \multirow{3}{*}{$\begin{array}{l}\text { Age } \\
\text { groups } \\
\text { in years }\end{array}$} & \multirow{2}{*}{\multicolumn{2}{|c|}{$\begin{array}{c}\text { Total } \\
\text { examined }\end{array}$}} & \multirow{2}{*}{\multicolumn{2}{|c|}{\begin{tabular}{|l} 
Males \\
Positive \\
\end{tabular}}} & \multirow{2}{*}{\multicolumn{2}{|c|}{$\begin{array}{c}\text { Females } \\
\text { Positive } \\
\end{array}$}} & \multirow{2}{*}{\multicolumn{2}{|c|}{\begin{tabular}{|l|} 
Total \\
Positive \\
\end{tabular}}} & \multicolumn{2}{|c|}{$\begin{array}{l}\text { Positive rate } \\
\text { from overall }\end{array}$} \\
\hline & & & & & & & & & & \\
\hline & No & $\%$ & No & $\%$ & No & $\%$ & No & $\%$ & No & $\%$ \\
\hline$\leq 1-10$ & 163 & 39.08 & 11 & 6.74 & 14 & 8.48 & 25 & 15.15 & 25 & $5.99 *$ \\
\hline $11-20$ & 43 & 10.31 & 2 & 4.65 & 1 & 2.32 & 3 & $\begin{array}{l}6.97 \\
\end{array}$ & 3 & 0.71 \\
\hline $21-30$ & 75 & 17.98 & 3 & 4.00 & 4 & 5.33 & 7 & 9.33 & 7 & 1.67 \\
\hline $31-40$ & 49 & 11.75 & 0 & 0.0 & 3 & 6.12 & 3 & 6.12 & 3 & 0.71 \\
\hline $41-50$ & 44 & 10.55 & 1 & 2.27 & 1 & 2.27 & 2 & 4.54 & 2 & 0.47 \\
\hline $51-60$ & 43 & 10.31 & 2 & 4.65 & 1 & 2.23 & 3 & 6.97 & 3 & 0.71 \\
\hline Total & 417 & 100 & 19 & 4.55 & 24 & 5.75 & 43 & 10.31 & 43 & 10.31 \\
\hline
\end{tabular}

The rate of Giardia lamblia $10.31 \%$ among IDPs in current study was not agree with the following ratios recorded in Iraq: 25.33 $\%, 30.39 \%, 35.89 \%, 37.5 \%, 44.59 \%$ and $45.9 \%$ for giardiasis in Kirkuk Province, Kirkuk city, Erbil, Al-Tammen, Basrah and Tikrit Provinces by (Kadir et al., 2000); (Kader and Salman,1999), (Kadir et al., 1987), (Jar-Allah, 2012) and (Al-Somadayi, 2012) respectively. Also the rate of giardiasis $10.31 \%$ in current study was lower than $18 \%, 25.33 \%, 62.2 \%, 67.6 \%$ and $89.5 \%$ recorded in Iran, Yemen, Egypt, Colombia and Chanaby (Taherkhan et al., 2009), (Al-Yousefi et al.,2013), (Yassin et al., 2000), (Jorge et al.,2009) and( Nkrumah and Nguash,2011) respectively. This finding reflects the degree of contamination with parasitic phases among this group of peoples in Kirkuk community. The reason to that most often might be related to nature of water consumption and water quality and water supply. It has been known, that a big construction for improving of roads and infra-structure in Kirkuk province from 2008 to 2014was carried on. This action lead to breakdown of water pipes underground, because all of these pipes are very old, this lead to continue of water supply interruption in this Province. The second reason to this high rate might be attributed to uncontrolled migration and inhabitation of IDPs to old buildings, in complete building, old schools. Moreover 4 to 5 families live in one house (highly crowded).All of these factors have had role in increasing the rate of intestinal parasites particularly giardiasis in current study. This finding was not agreed with those recorded in the same Province by (Salman et al., 2015), whom they record $7.05 \%$ of giardiasis among IDPs in the same governorate. It is not clear how much these differences may be explained by differences in study design, geographical location, population group, sensitivity of laboratory methods, stage of disease or type of laboratory tests.

Regarding common intestinal parasites records in current study particularly Blastocystishominis $4.17 \%$ as high rate rather than with other 8 parasites recorded, this finding was highlighting the alarm of the bad conditions of IDPs within areas whom they live. Moreover it has been found that there is relationship between Irritable bowel syndrome (IBS) and Blastocystis hominis infections (Ustun and Turjay, 2006). So this group of peoples(IDPs) may have bowel diseases predisposed by other psychiatric condition due to they were living under low level of poor hygienic conditions. 
This rate was lower than $1.66 \%$ that recorded among the IDPs in the same province by (Salman, et al 2105), whom they record $1.66 \%$ ). Also was not agreed $41.05 \%$ of Blastocystis hominis recorded by (Salman, 2015).Variances in the rate of Blastocystis mostly due to employee of ELISA copro-antigen test by the later author, who assess the efficacy of direct microscopy and ELISA in detecting Blastocystis hominis.

Comparison between the employ of direct double preparations technique and etherformalin sedimentation technique in detecting Giardia lamblia in stool samples, in this regard the obtaining of low efficacy of stool concentration method( formalinether technique)might be due to the light weight of Giardia lamblia parasites, which most often undergo flotation when it was in solution with high specific gravity as the used formalin-ether technique cannot permit that(WHO, 1991). While obtaining $6.23 \%$ of other intestinal parasites by using formalinether technique higher than $3.12 \%$ by using direct double wet preparations. This finding reflect that other intestinal parasites involve some helminthes recorded in current study, which have heavy weight that draw any heavy parasitic forms to the bottom of the tested tube containing stool sample plus parasites in this method( WHO,2003). This finding was agreed with those recorded by (Kadir and Salman,1999), (Salman and Ali,2013) and (Salman and Mustafa, 2013).

The result of the current study in regard of patient gender in relation to Giardia lamblia particularly and other intestinal parasites frequencies show no impact of gender in parasites distribution among IDPs. This finding was agreed with those reported in few studies done among different localities of Kirkuk governorate (Hayder, 1993) and (Al-somaydayi, 2012) and (Kader and
Salman,1999). And with that recorded by (Kadir and Al-Barzanji,2000) in Arbil and with that recorded by (Al-Hanoon, 1976) in Mosul whom they did not find significant difference in the rate of infection between males and females. While not agreed with that recorded by (Salman and Mustafa,2013), whom they recorded of giardiasis among males than in females in the same Province. No differences between two sexes are probably due to the different in technique used, or could be due to socioeconomic status.

Considering the age, recording of $15.55 \%$ of giardiasis and $5.99 \%$ from overall rate among children in age group from 6 months to 10 years compare to low rates in other age groups might be attributed to fact that this aged group peoples were spend most times out of the door so they were highly exposed to infectious agents including parasitic forms particularly Giardia parasite stages (Salman,2001). Malnutrition, due to poverty, which leads to immune diminishing had role in increasing the susceptibility of acquiescing infectious agents including Cryptosporidium and Giardia (Striepen, 2013) and (Watson et al.,2007). Conclusions: The overall rate of intestinal parasites, particularly giardiasis among young aging of IDPs in Kirkuk Province was high. Sedimentation (formalin-ether technique) of concentration method have had specific role in detecting intestinal parasites in stool samples of infected peoples than direct double wet preparation method.

\section{References}

Abd-Alzahra,E.;Shani, W.S and Al-Malak, M.Kh. (2012).Local and systemic immune responses in rats infected with Giardia lamblia. Med J. Baseah Univ ;30(1):60-72. 
Al-Hanoon, Z. (1976). Study of Prevalence of Intestinal Parasitic Infection in Mosul.M.Sc. thesis, College of Science, Mosul University, Iraq.

Alsomaedayi, I. (2012). Determination of Giardia lambliaassemblages and Entamoeba histolytical Entamoeba dispar complex by molecular diagnosis (PCR) in patient in Tikrit. Ph. D. thesis. Coll. Edu. Tikirit Univ.

Alyousefi, N.; Mahdy, M.; Xiao, L.; Mahmud, R. and Lim, Y. (2013).Molecular characterization of Giardia duodenalisin Yemen.EXP. Parasitol; 134(2):141-147.

El-safi,S.H.;Al-Magati, Th.N.; Hussien, M.I.; $\quad$ Adam,A.M.;Abu-Hassan, M.M.and Al-Zahrani,E.M. (2013). Comparison of microscopy, rapid immunoassay, and molecular techniques for the detection of Giardia lamblia and Cryptosporidium parvum. Parasitol Res;112:1641-1646.

Clinical and Laboratory Standard Institute (CLSI) (2005) Procedures for the recovery and identification of parasites from the intestinal tract; approved guidelines - second edition. CLSI Document M28-A2 (ISBN 1-56238572-0).

Daryani, A.; Sharif, M.; Nasrolahei, M.; Khaliliand, A.; Mohammadib, A.and Barzegara, Gh. (2012). Epidemiological survey of the prevalence of intestinal parasites among school children in Sari, northern Iran.Trans Roy Soc Trop Med hyg; 106: 455-459.

Dib, H.H.; Lu, S.Q. and Wen, S.F. (2008) Prevalence of Giardia lamblia with or without diarrhea in South East, South East Asia and the Far East. Parasitol Res 103(2):239-251.

Haydar, A. (1993). Study of the Prevalence of Human Intestinal Parasites in AlTameem governorate and the Effect of
Giardia lambliain Some Blood Components.M.Sc. thesis, College of Medicine, Salahaddin University, Iraq. Jarallah, H. (2012). Intestinal parasitic infections among rural villages in Basrah marshes regions. J of Basrah Res Sciences; 38(2): 40-43.

Jorge, H.; Otero-G.; Gisela, M.; Montoya, G.; Grisales-Patiño, D.; et. al. (2009).Giardia intestinalisand nutritional status in children participating in the complementary nutrition program, Antioquia, Colombia, May to October 2006.Rev.Instan. Med. Trop. S. Paulo; 51(3):501-506.

Kadir,M.; Kadir, A. and faraj, K. (1987). Survey study of intestinal parasites among different population of Erbil city. J. Fac. Med. Baghdad; 29(4):455459.

Kadir, M. and Salman,Y. (1999). Prevalence of intestinal parasites among primary school in Al- Taameem province, Iraq.Annals of the College of Medicine, Mosul; 25(1 \& 2):94-97.

Kadir, M.; AL-Mashhadani, A.; Tahir, S. and Chapook,G. (2000). A study on Giardia lambliainfection among patients attending primary health care centre in north oil company, Kirkuk.

Kadir, M. and Al-Barzanjy, R. (2000).Prevalence of Giardia lambliain Different Localities of Arbil province / Northern Iraq".Accepted in Med.J.Tikrit University.

Ndao,M.(2010) Diagnosis of parasitic diseases: old and new approaches. Inter-disc Perspect on Infect Dis 106(5):1127-1134.

Nkrumah, B. and Nguah, S. (2011). Giardia lamblia: a major parasitic cause of childhood diarrhoea in patients attending a district hospital in Ghana. Parasite and Vector; (4): 163-167 
Meyer EA (1990) Human parasitic diseases: giardiasis. In: Meyer EA (ed) Taxonomy and nomenclature. Elsevier, Amsterdam, pp 51-60.

Salman, Y.; Al-Alousi, T. and Hamad, S. (2001).Prevalence of intestinal parasites among people in Kirkuk city.AlmustansiriyaJ.Sci; 1: 12-20.

Salman,Y.J. and Ali,L.S.(2013).detection of some microbial infection among children aging below 2 years in Kirkuk city. J Kirkuk Med Coll;1(1):53-60.

Salman,Y.J.and Mustafa, M.I(2013). Evaluation of the employment of four laboratory diagnostic methods of detecting Gairdia lamblia among Children in Kirkuk city.JKirkuk Med Coll;1(2):52-60.

Salman, Y.J. (2014). Efficacy of some laboratory methods in detecting Giardia lamblia and Cryptosporidium parvum in stool samples. Kirkuk Univ.J. Sci. Stud., 9(1): 717.

Salman, Y.J. (2015). Detection of Blastocystis hominis among peoples in Kirkuk Province using ELISA and direct microscopy.Int. J. Curr. Microbiol.App. Sci., 4(10): 686695.

Salman, Y.J.;Kadir, M.A and Abdul-Allah,, T.J. (2015). Prevalence of Cyclospora cayetanensis and other intestinal parasites in soil samples collected from Kirkuk province. Int. J. Curr. Res. Aca. Rev., 3(10): 239250.

Salman, Y.J.; Sadek,W.S and Khorsheed, Z.R.(2015). Prevalence of Cryptosporidium parvum among Iraqi displaced people in Kirkuk city using direct microscopy, flotation technique and ELISA-copro antigen test.Int.J.Curr.Microbiol.App.Sci 4(11): 559-572.

Striepen, B. 2013. Parasitic infections: Time to tackle cryptosporidiosis. Nature, 513(7475): 189191.

Taherkhani, H.; Shariati, S.; Abdolahi, N. and Roshandel, G. (2009).Clinical Manifestations of Giardiasis in Iran.J. of clinic.and dia. Res;(3):1416-1418.

Ustun,S and Turjay,A. (2006). Blastocystis hominis and bowel diseases. Turkeyi Parazitol Drege; 30(1):72-76(Abstract in English).

Watson, J., Gayer, M. et al. (2007).Epidemics after natural disasters.Emerg. Infect.Dis., 13(1): 15.

World Health Organization(1991) Basic laboratory methods in medical parasitology.W.H.O Geneva :16-17.

World Health Organization(2003)Manual to medical laboratory investigations. WHO Geneva.

Xiao, L., Escalante, L., Yang, C. (1999).Phylogenetic analysis of Cryptosporidium parasites based on the small sub-unit rRNA. Gene locus.Appl. Environ. Microbial.,65: 1578-1583.

Yassin, M.; Shubir, M.; Al-Hindi, A. and JadAllah, S. (2000). Prevalence of intestinal parasites among children in Gezadistrict.J. Egy. Sco.parasitol; 2(29): 365-373.

\section{How to cite this article:}

Yahya Jirjees Salman, Abdul-Rahman Aziz Al-Taee and Ali Mohammed Abid. 2016. Prevalence of Giardia lamblia among Iraqi Displaced Peoples in Kirkuk Province. Int.J.Curr.Microbiol.App.Sci. 5(1): 753-760. hittp://dx.doi.org/10.20546/ijcmas.2016.501.070 